\title{
Temperament and Maternal Employment $\left({ }^{*}\right)$
}

\author{
JACQUELINE V. LERNER (**) \\ NANCY L. GALAMBOS (***)
}

Why is it important to study the relations between child temperament and maternal employment? Our answer to this question rests on the view that this relation is a useful sample case of a more general model of person-context relations, one that views the functional significance of any personological characteristics (for adjustment or adaptation or fit with the contextual demands) as involving bi-directional relations between individuals and their contexts. From this perspective the possession of any given individual characteristic does not necessarily have an invariant import for the adequancy of the individual's functioning. Instead, the import of any given individual attribute depends on how that attribute matches the «presses» (Murray, 1938), or demand (Thomas \& Chess, 1977) of the person's milieu (compare Bluss \& Plomin, 1984). A child who sleeps, eats, and eliminates in an irregularly timed pattern would be likely to have a different effect on parents who are highly routinized and scheduled that it would on parents who do not show such regular patterns. With the former type of parents arrhythmicity might lead to negative parent-child relations and result in poor child adjustment; with the latter type of parents

$\left(^{*}\right)$ Portions of this paper were printed in Temperament and Social Interaction During Infancy and Childhood (New Directions for Child Development, n: 31) (J.V. Lerner \& R.M. Lerner, Eds.), San Francisco: Jossey-Bass, March 1986.

(**) The Pennsylvania State University, USA.

(***) University of Victoria, Canada. arrhthmicity might not influence parent-child relations, and thus there would be no relationship to child adjustment (Lerner \& Lerner, 1983; Thomas \& Chess, 1977).

Elsewhere (Lerner \& Galambos, 1985; Lerner \& Lerner, 1983) we have described these relations among child characteristics, parental reactions, feedback, and resulting child behavior as child-context «circular functions» (Schneirla, 1957). Through the feedback a child receives as a result of his or her influences on others, the child acts as a producer of his or her own development (Lerner, 1982); the nature of the feedback received by the child has been discussed within the context of the «goodnessof-fit» model, a model that specifies positive feedback and child outcomes when there is a match between child characteristics and contextual demands and negative feedback and child outcomes when there is a mismatch between elements (Lerner \& Lerner, 1983).

The circular functions and "goodness-of-fit» concepts have been often examined in the context of assessing temperament features of child individuality (Lerner et al., 1986). Our research on the relations between child temperament and maternal employment extends this literature not only by appraising a most significant other in the child's world - the mother - but also by assessing the impact of potencial differences among mothers that accrue as a consequence of whether they are employed outside the home. Our assumption is that mothers who work outside the home exist in 
a broader ecological system (Bronfenbrenner, 1979), and they have demands imposed on them by virtue of their being embedded in this system. This embeddedness makes specific features of their child's temperament potencially very significant for the mother-child relationship, for feedback to the child, and for resulting child developments.

Specifically, children who have the temperament characteristics of arrhythmicity, negative mood, slow adaptability, high intensity of responses, and withdrawal are difficult to manage and to interact with easily; they do not respond efficiently to maternal care-giving attempts (Thomas et al., 1986). In fact, Thomas and Chess have labeled children possessing these temperament attributes as «difficult children». Contrasted with «easy children», who possess the temperament characteristics of high rhythmicity, positive mood, high adaptability, approach behaviors, and low to moderate intensity of responses, difficult children present management demands on any mother. These demands may be complicated when the mother exists within an extrafamilial (employment) system, which imposes its own demands, such as scheduled attendance, commitment, good performance, and efficiency. Simply, if a mother cannot get her child fed and to bed easily, and if the child does not regularly sleep through the night, the child will evoke reactions in the mother that will differ from those evoked by an easily fed child who goes to sleep readily and sleeps through the night. If a mother comes home from a day of work to face the difficult child, her relationship with the child will probably differ from the mother of a difficult child who is not strained by the additional extrafamilial role of work. Of course, another scenario is possible. It may be that the difficult child drives a mother out of the house; a mother might seek outside employment in order to escape from the strain of dealing with temperamentally difficult child. Either of these scenarios remains a logical possibility because of the quantity and quality of existent research. Our goal in this paper is to critique existing research in order to evaluate the current and potential use of studing the relation between child temperament and maternal employment as a sample case of our more general conception of person-contex bi-directional relations. This evaluation is of additional significance because current trends in maternal employment give the relation between maternal employment practical as well as theoretical significance. As of 1987 57 percent of married mothers with children under six were employed (U.S. Bureau of the Census, 1988). This percentage is higher for the single mothers and for mothers with older children. Thus, a focus on the potential relations between maternal employment and child development may provide information of considerable importance for many of today's families and those scientists and agencies concerned with planning policy issues pertinent to children, mothers, and families.

\section{ASSESSING RELATIONS BETWEEN CHILD TEMPERAMENT AND MATERNAL EMPLOYMENT}

What should be assessed in a research study to adequately test the relation between child characteristics (in our case, temperamental ones) and features of the context (maternal and family characteristics)? While it is clear that such research should be longitudinal in order to appraise the circular functions between child and context that we wish to explore, other features must include: (1) An adequate assessment of child individuality: Some theoretically relevant feature of the child must be measured in a psychometrically appropriate manner. Here a representative research question would be, do employed mothers have children whose temperament characteristics differ from temperament characteristics of children of non-employed mothers?; (2) An appraisal of the influences of this characteristic of child individuality on the mother: This is the assessment of «child effects" (child-mother). Here a representative research question would be, Do children possessing particular temperament characteristics influence behaviors, attitudes, and so on, of their employed mothers in manners that correspond to the way in which children having these same characteristics influence their nonemployed mothers?; (3) An appraisal of the reaction of the mother to her child: This component can be, and typically may be, a component of the second point just mentioned. 
But it is logically and empirically possible to treat this as a separate component. Here a representative research question would be, Are the attitudes of employed mothers toward their child's temperament characteristics comparable to the attitudes of non-employed mothers to their child's (same) temperament characteristics? (4) An assessment of the feedback shown by the mother to the child: Here one may assess either a mother's behaviors, attitudes, and so on, toward the child (in regard to her «parenting style», see Baumrind, 1971) on her interactions with the child. The former assessment may be represented as "child-mother» and the latter as "child-mother». A representative research question would be, Do employed mothers have an approach different from non-employed mothers toward interacting with children or rearing who have particular sets of temperament attributes?; (5) An appraisal of behavioral and attitudinal outcomes in the child: Here a representative research question would be, Do children with particular temperament attributes and employed mothers differ on child development outcomes from children with the same temperament characteristics and non-employed mothers?

No single research study has longitudinally evaluated all components of circular functions between the child temperament and maternal employment. However, we can use the five features of assessment as a means of discussing existent research on the basis of how it bears on components of the circular functions and whether it meets the other methodological criteria we shall specify.

This analysis will indicate not only where existent research fits into our model, but also where confidence can be placed in available data, and where, in fact no data exist. This analysis will be followed by a final section, indicating some of the key issues that remain to be addressed in order to more adequaly use the child temperament-maternal employment relation as a sample case of how children, through bi-directional relations with their social context, influence their own development.

\section{THE INFLUENCE OF CHILD TEMPERAMENT ON MATERNAL BEHAVIORS AND MATERNAL EMPLOYMENT}

Before we discuss research directly pertaining to the child temperament-maternal employment relationship, it is of use to note research that has evaluated the influence of temperament on care-givers' behaviors. Crockenberg (1986) reviews the literature regarding the effect that the temperament characteristics of negative emotionality in infancy (for example, fear, distress, negative mood, and high intensity of reaction) has on maternal care-giving behaviors. Although she concludes that the relationship between infant temperament and care-giving behavior has not been adequately tested, several studies do report associations. Briefly, several studies find that babies who are defined as irritable or has having difficult temperament receive responsive care-giving or less stimulating contact from their mothers (Crockenberg \& Acredolo, 1983; Dunn \& Kendrick, 1980; Kelly, 1976; Klein, 1984; Linn \& Horowitz, 1983; Milliones, 1978; Peters-Martin \& Wachs, 1984). The associations reported in these studies are far from unequivocal, however. In many of the studies maternal behavior and infant temperament are not independently measured, allowing for a potencially inaccurate influence of maternal behavior on infant temperament due to common method variance. Although these studies did not deal with the distinction between employed versus non-employed mothers, they have addressed some of the same general issues raised. That is, they have appraised the reactions of mothers (in terms of attitudes and behaviors) to children possessing different temperament characteristics. These studies do not have the methodological features necessary to adequately assess the «circular functions» feedback model that we propose to be operating; specifically, they do not longitudinally assess the child's characteristics, the influence of these characteristics on the mother's behavior, the feedback the child receives, and the nature of the child's outcomes. However, the significance of these results for the temperament are associated with differences in mothers' behavior.

Some studies that do employ relatively independent measures of maternal behavior and infant temperament have found that mothers are less engaged with their babies if they are difficult or irritable (Crockenberg \& Acredolo, 1983; Linn \& Horowitz, 1983). These studies are countered by findings of studies reporting 
that mothers of difficult or irritable babies are more engaged with their babies than are mothers of easy, less irritable babies (Bates et al., 1982; Caron \& Miller, 1981; Crockenberg \& Smith, 1982; Fish \& Crokenberg, 1981; Klein, 1984; Peters-Martin \& Wachs, 1984; Pettit \& Bates, 1984). Crockenberg notes that several factors may be responsible for the inconsistent findings, for example, curvilinear effects mothers increasing their involvement in relation to their infants' needs and withdrawing only if the infants are extremely difficult or irritable; the influence of some third variable such as maternal attitudes or the sex of the infant; or an interaction between temperament and some other characteristic of the care-giver or caregiving environment.

To extend this discussion of the association between infant temperament and maternal caregiving behaviors to maternal employment, we may note that the decision to work outside the home will indeed be influenced by many of the same variables - maternal attitudes, sex of child, temperament of child, and interactions among these variables. Lamb, Chase-Lansdale, and Owen (1979) were among the first to discuss maternal employment in the context of considering how characteristics of the infant, such as temperament and physical attractiveness, may influence maternal perceptions and perhaps even the mother's decision to work outside of the home. In terms of temperament, they note that mothers who perceive their babies as difficult are less sensitive to their cues and signals (Donovan \& Leavitt, 1977; Donovan, et al., 1978) and have less sympathy for "difficult» infants (Frodi, et al., 1978). Lamb et al. (1979) speculated that the frustation that ensues in caring for a difficult infant may decrease the value of care-giving and lead the mother to feel she would rather work outside the home. On the other hand, the positive rewards of caring for an easy infant may either reinforce a mother's decision not to work outside the home or lead a mother to believe that the infant is adaptable enough to be left with another caregiver.

Some advances in regard to assessing the bidirectional relationships between employed mothers and their infants have been made. For example, the notion of bi-directional relations between the mother and infant is introduced and the temperament of the child considered a salient variable in a study by Hock, Christman and Hock (1980). They examined differences between mothers who at their child's birth, where not going to work but changed their minds (inconsistent mothers) and those who stayed at home during the infant's first year (consistent mothers). Mothers who were inconsistent (they returned to work) were more career-oriented, expressed more negative attitudes about the maternal role, and more often considered employment important. With respect to mother-infant relationship, inconsistent mothers were more concerned with and expressed a stronger aversion to the infant's fussiness, although they did not perceive their infants as more difficult than did consistent mothers.

In another study Hock (1980) observed infants' actual behaviors in the Ainsworth and Wittig Strange Situation Assessment. Results indicated that infants of employed mothers did not exhibit different social behaviors or score differently on developmental indices (such as the Mental Development and Developmental Index of the Bayley Scales of Infant Development) from infants of nonemployed mothers. More importantly, Hock reported that mothers whose work status was incongruent with their beliefs about exclusive mothering (for example, those mothers who were employed but believed in exclusive mothering or those who were not employed and did not believe in the need for exclusive mothering) had infants who exhibited more frequent and intense behavior directed toward the mother at the time of the reunion.

The sudies by Hock (1980), and Hock, Christman, and Hock (1980) have adressed many of the issues discussed here as necessary to appraise the circular functions between child and context: They have focused on differentiating between employed versus non-employed mothers and have assessed the child's characteristics (as displayed in the strange situation, that is, fussing, crying, contact with mother, and so on), the mother's attitudes, beliefs, and work status, and how they may influence the motherchild relationship. In addition, Hock considered the influence of the infant's behaviour on the mother's feelings. Thus, these findings are 
important ones for the study of how the child's characteristics affect the mother early in the child's life. To extend this line of study to answer the five questions we outlined earlier, one would need to directly assess the feedback that the mother gives the child and the child's subsequent developmental outcomes as a result of such feedback.

McBride and Belsky (1985) also have found that infant characteristics may influence maternal decisions to work outside the home, thus supporting the notion that the child is an active agent in determining the nature of his or her social environment. This study used infant-mother pairs from the second and third cohorts of the Pennsylvania Infant and Family Development Project ( $\mathrm{N}$ for Cohort $2=64, \mathrm{~N}$ for Cohort $3=118$; Belsky et al., 1984). Characteristics of the infant were determined by one - and five-minute Apgar scores, the Brazelton Neonatal Behavioral Assessment Scale (NBAS), mothers' ratings of infant temperament, and home observations of infant behavior. Mothers were asked prenatally about their plans to work during the child's infancy, and actual work status was determined at three months postpartum. For Cohort 2, results indicated that women who were not working at three months postpartum had infants who displayed a more difficult, fussy temperament. In addition, mothers who planned to work at three months but who were not employed had infants with lower Apgar scores and lower scores on the NBAS. They were also less alert and responsive during observations. Identical analyses were conducted with respect with Cohort 3 , but these revealed no significant differences with respect to the infant's temperament. However, a similar trend, although insignificant, was obtained for the group of women who were not employed at three months but had planned to be. That is, their infants had lower Apgar and NBAS scores, were less alert and responsive during observations, and were reported to be more fussy and difficult.

The results of McBride and Belsky (1985) are good illustrations of the use of some of our assessment criteria. That is, the results show the value of assessing the relationship between child temperament and maternal employment by assessing longitudinally the influence of temperament characteristics on the mother's decision to work outside the home. Indeed, we see from these results that the temperament characteristics a child possesses play a role in shaping his or her context, in this case, whether or not the mother enters or re-enters the labor force. However, because the nature of the feedback (such as maternal behaviors, positive or negative mother-child interaction, maternal parenting style) from the mother to the child was not addressed, this study did not provide a complete test of the circular functions model. However, we may speculate that the infants who were difficult receive more negative feedback from their mothers, especially in cases in which the mother planned to be working after the birth of the child but was not. Such feedback, in turn, would have a negative influence on the child's subsequent development.

In another study focused on the influences of child characteristics on maternal employment, Galambos and Lerner (1987) investigated the relative influence of child, maternal, and demographic characteristics on the labor force participation of mothers with young children. The sample was composed of ninety-three mothers and their children from intact families who had been followed in the New York Longitudinal Study (NYLS) for the past twenty-five years. The relationships between the mother's work status and the child's physical problems and temperament, the mother's family orientation and rejection-acceptance of the child, and demographic features such as the mother's education, the father's occupational prestige, and the number of young children in the family, were investigated at three points in time: during the child's infant, toddler, and preschool years.

Multiple regression analyses revealed that child characteristics were as potent as demographic features in predicting the mother's labor force activities. Specifically, the level of a child's difficult temperament (for example, irregularity of biological functions, withdrawal responses, high intensity of reactions, negative mood, and slow adaptability) and the presence of chronic physical problems (such as asthma or chronic respiratory illnesses) in infancy were related to lower levels of employment for the mother during the child's infancy and toddlerhood. In addition, the greater the number of children 
under age six when the target child was age three and five, the less likely the mother was to be employed outside of the home during the child's toddlerhood years. These were illustrative findings of multiple (and multilevel) influences on development and of the embeddedness of the child temperament-maternal employment relation within the broader person-context model from which our interest in this relation is derived. These findings were that the child's difficult temperament, as measured in infancy and toddlerhood, the number of young children present when the target child was three and five years old and the presence of physical problems in the child, accounted for 23 percent of the variance in the mother's labor force participation during the toddler years and 22 percent of the variance in the mother's labor force participation in the preschool years. However, neither of the maternal attitudes - rejection of the child and family orientation - was significantly related to the mother's level of employment at any stage. The father's occupational prestige and the mother's level of education also failed to correlate significantly with the mother's work status. Furthermore, difficult temperament during the preschool years and the number of children when the child was in his or her first year were not related significantly to the mother's employment.

In sum, in the highly educated, middle to upper-middle class NYLS sample, characteristics of the child such as temperamental style and physical problems contributed significantly to the mother's decision to be gainfully employed in the child's early years. Although child characteristics alone did not explain a great deal of the variance (ranging from 8 percent to 18 percent), the results suggest that features of the child may play a role in the mother's career development and should be included in future studies of women's labor force participation patterns. These results, along with those of McBride and Belsky (1985), suggest that a child who has a difficult temperament or who has physical problems that require more intensive care may present too many demands on a mother who, under less stressful conditions, may pursue employment. The high association between the number of young children in the family and mother's employment status, a finding that is consistent with other studies (see Hoffman, 1974), reinforces the notion that family demands may depress the mother's level of employment. Of course, the direction of causality in the Galambos and Lerner (1987) study was not determined, and it could be that the child of the mother who is employed becomes less demanding. In fact, the child's temperament during toddlerhood was related to the mother's maternal employment status during the child's first year. These findings are consistent, then, with the idea that the relationship between the mother's employment and the child's characteristics are characterized by bi-directionality and, therefore, future research should address the issue of causal relations.

Of course, the direct effect of the child's temperament on the mother's labor force participation is only one aspect of the child temperament-maternal employment relationship that can be, and has been, addressed. Certainly, all mothers of "difficult» children cannot and do not simply reject the idea of employment outside of the home. One might ask: (1) What are the conditions under which a particular type of temperament influences a mother's employment status? or, (2) Through what means does temperament influence the mother's experiences, attitudes, and feelings and thereby influences her employment status?

With the exception of one investigation (Lerner \& Galambos, 1985), no studies have examined how the child's temperament influences the mother once the employment decision has been made. It is worth hypothesizing that the mother of an irritable infant or child may be more moody in the work setting because she is anxious about the child's welfare. On the other hand, we have noted that the mother of a more difficult child could find work an escape from the demands of child care. Whether the employed mother of a child with a difficult temperament feels more strained by the challenges of work and childrearing remains an open empirical question. We would not expect a simple relationship to exist, however. Rather, the employed mother will bring to her situation many beliefs, capabilities, and problems and a level of social support that will influence her interactions with her child, the nature of which 
may also be affected by the particular job and home situation (hours of work, job demands, and other familial demands).

Lerner and Galambos (1985) investigated the bi-directional relations between the child's temperament and the mother's satisfaction with her role (whether she was employed or not). Using eighty-nine mother-child pairs from the NYLS data set, Lerner and Galambos used a path analytic model to investigate the relationship between child difficulty at age two and maternal role satisfaction at age three, and the relationship between maternal role satisfaction at age three and child difficulty at age four. We were interested in whether role satisfaction (age three) influenced subsequent child difficulty (age four) and whether prior child difficulty (age two) influenced role satisfaction (age three). We found that role satisfaction influenced subsequent child difficulty, but earlier childhood difficulty did not influence subsequent maternal role satisfaction. This could be due to the methodological limitations of the study, such as measurement problems and small samples sizes. However, some findings did emerge that are relevant for the present discussion of childcontext relations.

As part of the same analytic model, we tested whether the maternal characteristic of role satisfaction (at age three) influenced subsequent child difficulty (at age four) through the «process» of mother-child interaction at age three (in this case, maternal rejection). Results indicated that maternal role satisfaction did not significantly influence child difficulty directly; however, maternal role satisfaction was significantly related to maternal rejection (with dissatisfied mothers displaying higher levels of rejection), and maternal rejection was significantly related to later child difficulty (with more difficulty chidren having more rejecting mothers). Although our test for the influences of child temperament on the mother's role satisfaction was not borne out by the data, our findings do show that maternal characteristics did indeed influence the child. As mentioned earlier, no study to date has sufficiently tested the child-context relations model we have presented. However, existing data supporting parts of this model lead us to believe that our assessment foci is worthy of further study when examining the relationship between temperament and maternal employment.

\section{IMPLICATIONS AND DIRECTION FOR FUTURE RESEARCH}

While the existent information as to the nature of the relationship between child temperament and maternal employment is small, it is sufficiently clear in indicating that future empirical pursuit of their relationship may be rewarded with a better understanding of how individual characteristics of the child may interact with maternal experiences and decisions. We note here some limitations of the available research in order to aid in the direction of future research along possibly more fruitful paths.

First, in general, there has been a failure to look at the bi-directionality of child temperament and maternal employment. The studies by Hock (1980; Hock et al., 1980) conceptualize the mother's employment or non-employment primarily as dependent on the mother's feelings about her career, her concerns about the infant, and her beliefs about mothering. Hock (1980) sought to determine how the mother's feelings appeared to influence the infant's behaviors; this is a worthy goal but is only one side of a potentially bi-directional relationship.

A second limitation of some available studies concerns independence of measurements. For example, Hock, Christman and Hock (1980) and Lerner and Galambos (1985) and Galambos and Lerner (1987) relied on the mothers' reports for measures of maternal perceptions, attitudes, and feelings, as well as for the indices of the children's temperament characteristics. Given the nature of the data, it is unclear to what extent the children's temperament ratings are influenced by the mothers' characteristics, and if an independent rater would see the children in the same light. Fortunately, some research has used multiple modes of assessment (Hock, 1980; McBride \& Belsky, 1985), including observations of the child, thus allowing less equivocal conclusions to be made about the relationship between the child's temperament and the mother's employment. These studies tend to corroborate the relationships reported in studies using only maternal reports. For example, 
Galambos and Lerner (1987) and McBride and Belsky (1985), report essentially the same findings with respect to the relationship between maternal employment and child temperament, that is, that child difficulty is related to the mother not being employed.

A third limitation of studies reviewed here is that the father has been neglected as a potent force in influencing both the mother's employment experiences and the behavior of the child. The father may play a role in the mother's decisions to seek employment or to continue employment, for example, in regard to the emotional and care-giving support he provides. His attitudes, in fact, may be influenced by what he believes are the child's needs. In line with the notion of bi-directional relations, then, the child's temperament (or other characteristics) may influence the father's beliefs. Future studies would do well to investigate the nature of the relationship between the mother, the father, and the child.

One powerful way of investigating this kind of relationship is exemplified by designs assessing the mother's desire before the child's birth to be employed in the first year of the infant's life or shortly after the baby's birth (Hock, 1980; Hock et al., 1980; McBride \& Belsky, 1985). The mother's career orientation, in this case, is not confounded by her knowledge of the infant's characteristics. The father's attitudes could also be assessed prior to the infant's birth. As the child develops, repeated assessments of the father's and mother's attitudes and feelings could be made, along with detailed information about the mother's employment status and the child's temperament. As the mother, father, and child move into new relationships with each other and develop further, a great deal of knowledge may be gained by teasing apart the web of interrelationships as they become established over time. Thus, longitudinal research may be most informative with respect to learning more about maternal employment and child temperament.

We have learned that the mother's decision to be employed may be affected by her child's temperament, with available data suggesting that the mothers of more difficut children tend to choose the homemaker role. Future research might profitably follow two different but related lines of inquiry. First, we might ask: How does the child's changing temperament influence the timing of the mother's entry into the labor force? This question longitudinally focuses on the mother's employment decisions and behavior. A subsidiary question, which could be asked within the same study is: How is the timing of the entry influenced by the father's and mother's cognitions and reactions to each other and to the child?

The second line of inquiry would be exemplified by the following set of research questions: How are the mother's experiences in the workplace shaped by the characteristics of her child? That is, most research on maternal employment has investigated how the mother's employment situation influences the child's characteristics. In addressing the other side of the relationship we might ask: Do the child's characteristics influence the mother's choice of occupation, the satisfaction she feels with respect to her employment? While these questions are as unidirectional as previous research that looked at the effects of maternal employment on the child, the underlying theme is to understand ongoing bi-directional relations.

The issue of maternal employment and child temperament is an important one that has potentially exciting possibilities with respect to understanding child development from the perspective of a person-context bi-directional model. The child is an active organism, one that may have powerful effects on his or her own development and on the development of significant others. We are only beginning to understand the child's influence on the mother's occupational development, and we hope that future research endeavors explore this possibility further.

\section{REFERENCES}

Bates, J., Olson, S., Pettit, G. \& Bayles, K. (1982). Dimensions of Individuality in the Mother-Infant Relationship at Six Months of Age. Child Development, 53: 446-461.

Baumrind, D. (1971). Current Patterns of Parental Authority. Developmental Psychology Monographs, 4: 1-103.

Belsky, J., Gilstrap, B. \& Rovine, M. (1984). The 
Pennsylvania Infant and Family Development Project, I: Stability and Change in Mother-Infant and Father-Infant Interaction in a Family Setting: One-to-Three-to-Nine Months. Child Development, 55: 692-705.

Bronfenbrenner, U. (1979). The Ecology of Human Development. Cambridge, MA: Harvard University Press.

Buss, A.H. \& Plomin, R. (1984). Temperament: Early Developing Personality Traits. Hillsdale, NJ: Erlbaum.

Caron, J. \& Miller, P. (1981). Effects of Infant Characteristics on Caretaker Responsiveness Among the Gusii. Paper presented at the biennial meeting of the Society for Research in Child Development, Boston.

Crockenberg, S. \& Acredolo, C. (1983). Infant Temperament Ratings: A Function of Infants, or Mothers, or Both? Infant Behavior and Development, 6: 61-72.

Crockenberg, S. \& Smith, P. (1982). Antecedents of Mother-Infant Interaction and Infant Irritability in the First Three Months of Life. Infant Behavior and Development, 5: 105-119.

Crockenberg, S.B. (1986). Are temperamental differences in babies associated with predictable differences in caregiving? In Temperament and Social Interaction in Infants and Children (J.V. Lerner \& R.M. Lerner, Eds.). New Directions for Child Development, 31, San Francisco: JosseyBass.

Donovan, W.L. \& Leavitt, L.A. (1977). Early Cognitive Development and Its Relation to Maternal Physiologic and Behavioral Responsiveness. Paper presented to the Society for Research in Child Development, New Orleans.

Donovan, W.L., Leavitt, L.A. \& Balling, J.D. (1978). Maternal Physiological Responses to Infant Signals. Psychophysiology, 15: 68-74.

Dunn, J. \& Kendrick, C. (1980). Studying Temperament and Parent-Child Interaction: Comparison of Interview and Direct Observation. Developmental Medicine and Child Neurology, 22: 484-496.

Fish, M. \& Crockenberg, S. (1981). Correlates and Antecedents of Nine-Month Infant Behavior and Mother-Infant Interaction. Infant Behavior and Development, 4: 69-81.

Frodi, A.M., Lamb, M.E., Leavitt, L.A. \& Donovan, W.L. (1981). Fathers' and Mothers' Responses to Infant Smiles and Cries. Infant Behavior and Development, 1: 187-198.

Galambos, N.L. \& Lerner, J.V. (1987). Child Characteristics and the Employment of Mothers With Young Children: A Longitudinal Study. Journal of Child Psychology and Psychiatry, 28: 87-98.
Hock, E. (1980). Working and Nonworking Mothers and Their Infants: A Comparative Study of Maternal Care-giving Characteristics and Infant Social Behavior. Merrill-Palmer Quarterly, 26: 79-101.

Hock, E., Christman, K. \& Hock, M. (1980). Factors Associated with Decisions About Return to Work in Mothers of Infants. Development Psychology, 16: $535-536$.

Hoffman, L.W. (1974). The Employment of Women, Education, and Fertility. Merrill-Palmer Quarterly, 20: 99-119.

Kelly, P. (1976). The relation of Infant's Temperament and Mother's Psychopathology to Interactions in Early Infancy. In The Developing Individual in a Changing World (K.F. Riegel \& J.A. Meacham, Eds.). Chicago: Aldine.

Klein, P. (1984). Behavior of Israeli Mothers Toward Infants in Relation to Infants' Perceived Temperament. Child Development, 55: 1212-1218.

Lamb, M.E., Chase-Lansdale, L. \& Owen, M.T. (1979). The Changing American Family and Its Implications for Infant Social Development: The Sample Case of Maternal Employment. In The Child and Its Family (M. Lewis \& L.A. Rosenblum, Eds.). New York: Plenum.

Lerner, J.V. \& Galambos, N.L. (1985). Maternal Role Satisfaction, Mother-Child Interaction, and Child Temperament. Developmental Psychology, 21: 1157-1164.

Lerner, J.V. \& Lerner, R.M. (1983). Temperament and Adaptation Across Life: Theorical and Empirical Issues. In Life-Span Development and Behavior (P.B. Baltes \& O.G. Brim, Jr., Eds.) (Vol. 5). New York: Academic Press.

Lerner, R.M. (1982). Children and Adolescents as Producers of Their Own Development. Developmental Review, 2: 342-370.

Lerner, R.M., Lerner, J.V., Windle, M., Hooker, K., Lenerz, K. \& East, P.L. (1986). Children and Adolescents in Their Contexts: Tests of a Goodness of Fit Model. In The study of Temperament: Changes, Continuities, and Challenges (R. Plomin \& J. Dunn, Eds.). Hillsdale, NJ: Erbaum.

Linn, P. \& Horowitz, F. (1983). The Relationship Between Infant Individual Differences and Mother-Infant Interaction During the Neonatal Period. Infant Behavior and Development, 6: 415-427.

McBride, S.L. \& Belsky, J. (1985). Maternal Work Plans, Actual Employment, And Infant Temperament. Paper presented at the Biennial Meeting of the Society for Research in Child Development, Toronto.

Milliones, J. (1978). Relationship Between Perceived 
Child Temperament and Maternal Behaviours. Child Development, 49: 1255-1257.

Murray, H.A. et al. (1938). Explorations in Personality. New York: Oxford University Press.

Peters-Martin, P. \& Wachs, T. (1984). A Longitudinal Study of Temperament and Its Correlates in the First 12 Months. Infant Behavior and Development, 7: 285-298.

Pettit, G. \& Bates, J. (1984). Continuity of Individual Differences in the Mother-Infant Relationship from 6 to 13 Months. Child Development, 55: 729-739.

Schneirla, T.C. (1957). The Concept of Development in Comparative Psychology. In The Concept of Development (D.B. Harris, Ed.). Minneapolis: University of Minnesota Press.

Thomas, A. \& Chess, S. (1977). Temperament and Development. New York: Brunner/Mazel.

Thomas, A., Chess, S. \& Birch, H. (1968). Temperament and Behavior Disorders in Children. New York: New York University Press.

United States Bureau of the Census (1988). Current Population Reports, Serie P-20, № 427, Fertility of American Women: June 1987, U.S. Government Printing, Washington, DC.

\begin{abstract}
This paper explores the relation between child temperament and maternal employment. We view this relation as a sample case of a more general model of person-context relations and we review the literature which has addressed this relation. Children possess different behavioral or temperamental
\end{abstract}

characteristics which affect their interactions with their caregivers. In this regard, children possessing certain temperamental characteristics influence the behavior and attitudes of their employed mothers. In fact, research has shown that a child's temperament may even influence the mother's decision to be employed or not. Research has also appraised the behavioral outcomes that result for the child. For example, children whose temperaments are «difficult» show less optimal functioning than children whose temperaments are «easy». Methodological limitations of the research which explores the child temperamentmaternal employment link is discussed.

\section{RESUMO}

$O$ artigo explora a relação entre o temperamento do bebé e o emprego da mãe. Esta relação é analisada como um modelo de relações pessoa-contexto, sendo revista a literatura que aborda este assunto. As crianças possuem características comportamentais ou temperamentais diferentes que afectam as suas interacções com as pessoas que cuidam delas. De facto, a investigação existente já mostrou que o temperamento da criança pode mesmo influenciar a decisão da mãe para se empregar ou não. A investigação também avaliou os resultados que este aspecto tem sobre o comportamento da criança. Por exemplo, as crianças com temperamento difícil revelam um funcionamento menos óptimo do que as crianças «fáceis». São discutidas as limitações metodológicas da investigação que explora a ligação entre o temperamento da criança e o emprego da mãe. 